\title{
Simultaneous Bilateral Proximal Humeri Anterior Fracture Dislocations in a Patient with 1st Onset Seizure. A Case Report and Review of the Literature
}

\author{
Kelvin G Tan, MBBS, Sathappan SS, FRCS (Ed) (Orth), Ganesan N R, FRCS (Ed) (Orth) \\ Department of Orthopedic Surgery, Tan Tock Seng Hospital, Singapore
}

\begin{abstract}
Bilateral anterior fracture-dislocations of humeral neck in a patient with seizure are extremely rare. We describe a rare case of a 33 -year-old Chinese gentleman who presented post seizure secondary to subdural gliosis, sequelae from a previous subdural haematoma. Following physical examination and radiographic assessment, including a Computed Tomography scan (CT scan), Rarely fracturedislocation of bilateral proximal humeri were diagnosed; similar fracture patterns were noted. Open reduction and internal fixation with PHILOS proximal humeral locking plate allowed early shoulder rehabilitation.
\end{abstract}

Key Words:

Bilateral Proximal Humeri; Bilateral Humeral Necks; Anterior Fracture-dislocations; Seizure; Subdural Gliosis, Subdural Haematoma

\section{INTRODUCTION}

Fracture-dislocation of the proximal humerus is typically associated with epilepsy, electrocution or extreme trauma, the so-called "Triple E" syndrome coined by Brackstone ${ }^{1}$. Bilateral fracture-dislocations of the proximal humeri are usually posterior and associated with convulsive episodes. We describe a rare case of a patient who suffered simultaneous bilateral anterior humeral neck fracturedislocations in a patient with a first onset seizure. He subsequently underwent open reduction internal fixation of both fractures.

\section{CASE REPORT}

A 33 year old Chinese gentleman was admitted to the emergency department with a confirmed first episode of generalised tonic clonic (GTC) seizure. He had a past history of schizophrenia and bipolar disorder, and was on appropriate medications, and a history of previous head injury with right frontal subdural haematoma. Computed Tomography (CT) scan of the head and electroencephalogram (EEG) were performed and, the patient was referred to a neurologist with clinical impression of onset of seizure secondary to subdural gliosis. On presentation, he also complained of severe bilateral shoulder pain with difficulty in movement of both shoulders. Physical examination findings include bilateral shoulder ecchymoses, flattening of both shoulders, restricted and painful movements in all ranges of shoulder joints. Radiological investigation revealed fractures of bilateral proximal humeri (Figure 1). CT scans of both shoulders were ordered to further evaluate the fractures and to assist in preoperative planning for surgery (Figure 2). Symmetrical fracture patterns were noted with anterior dislocations of both fractured humeral necks, the right being a 3-part fracture, the left being a 4-part fracture, according to Neers classification ${ }^{2}$. He underwent open reduction and internal fixation of both fractures.

The patient was placed in a standard beach chair position for surgery. Operative details for both sides were largely similar, with a standard deltopectoral approach employed for both sides in followed by blunt dissection through the deltoid muscle. The joint capsule was divided and the fracture site directly visualised; the fracture was reduced and the humeral head was initially secured to the glenoid with K-wires. The PHILOS proximal humerus locking plate was used, and the remaining fragments were held to the plate with ethibond followed by K-wire removal. The deltoid muscles and joint capsule were repaired.

Physiotherapy was started on the first postoperative day including passive shoulder mobilisation exercises and subsequently adding progressive active range of motion exercises and strengthening exercises. The patient was discharged after 5 days of uneventful hospital postoperative recuperation.

At five months post-operative follow-up, the fracture had united and there was no radiological evidence of avascular necrosis (Figure 3). He had painless range of motion of both shoulder joints (Figure 4). His active range of motion were as follow. Right shoulder: Forward elevation, 150 degrees; Abduction, 120 degrees; External rotation, 30 degrees; Internal rotation, to level of L2 vertebra. Left shoulder: forward elevation, 50 degrees; Abduction, 60 degrees; External rotation, 10 degrees; Internal rotation, to L2. He has gone back to work as a marine engineer. 
Table I: Summary of case reports of bilateral anterior dislocations associated with 3- or 4- parts proximal humeral fractures.

\begin{tabular}{|c|c|c|c|c|c|c|}
\hline Authors & Biodata & Cause & $\begin{array}{l}\text { Mechanism of } \\
\text { dislocation }\end{array}$ & $\begin{array}{l}\text { Associated } \\
\text { fractures }\end{array}$ & Treatment & Outcome \\
\hline Sharma et al. 2005 & $\begin{array}{l}42 \text { years } \\
\text { old/Male/ } \\
\text { manual } \\
\text { labourer }\end{array}$ & $\begin{array}{l}\text { Heavy object } \\
\text { falling over his } \\
\text { back }\end{array}$ & $\begin{array}{l}\text { Bilateral } \\
\text { Anterior }\end{array}$ & $\begin{array}{l}\text { Bilateral 3-part } \\
\text { fracture of both } \\
\text { humeri with right } \\
\text { rotator cuff tear }\end{array}$ & $\begin{array}{l}\text { Bilateral ORIF } \\
\text { with multiple } \\
\text { K wires. } \\
\text { Right rotator } \\
\text { cuff repaired }\end{array}$ & $\begin{array}{l}\text { Resumed work } 3 \\
\text { months later. } \\
\text { Right-flex } 110^{\circ} \text {, } \\
\text { abduct } 100^{\circ}, \\
\text { Left-Flex } 100^{\circ}, \\
\text { abduct } 95^{\circ}(1 \mathrm{yr}) \text {. }\end{array}$ \\
\hline Timo et al. 2003 & $\begin{array}{l}44 \text { years } \\
\text { male }\end{array}$ & $\begin{array}{l}\text { Hypoglycemia } \\
\text { convulsion }\end{array}$ & $\begin{array}{l}\text { Bilateral } \\
\text { anterior }\end{array}$ & $\begin{array}{l}\text { Bilateral 3- part } \\
\text { fracture of both } \\
\text { humeri with left } \\
\text { rotator cuff tear }\end{array}$ & $\begin{array}{l}\text { Bilateral (AO) } \\
\text { T Plate. } \\
\text { Left rotator } \\
\text { cuff repaired }\end{array}$ & $\begin{array}{l}\text { Able to work at } \\
15 \text { months. } \\
\text { Right-flex } 170^{\circ} \text {, } \\
\text { abduct } 160^{\circ} \text {. } \\
\text { Left- flex } 160^{\circ} \text {, } \\
\text { abduct } 150^{\circ} \text {. }\end{array}$ \\
\hline Duman H. 2000 & $\begin{array}{l}\text { 56-year- } \\
\text { old } \\
\text { female/ } \\
\text { housewife }\end{array}$ & $\begin{array}{l}\text { Accidental } \\
\text { electrical } \\
\text { injury/ } \\
\text { Household } \\
\text { appliance }\end{array}$ & $\begin{array}{l}\text { Bilateral } \\
\text { anterior }\end{array}$ & $\begin{array}{l}\text { Bilateral 3-pt } \\
\text { fracture }\end{array}$ & $\begin{array}{l}\text { Right- K wires } \\
\text { and screw } \\
\text { Left- } \\
\text { hemiarthroplasty }\end{array}$ & $\begin{array}{l}\text { Full range of } \\
\text { motion of both } \\
\text { shoulders in } 3 \\
\text { months (no } \\
\text { documented } \\
\text { details of range } \\
\text { of motion) }\end{array}$ \\
\hline
\end{tabular}

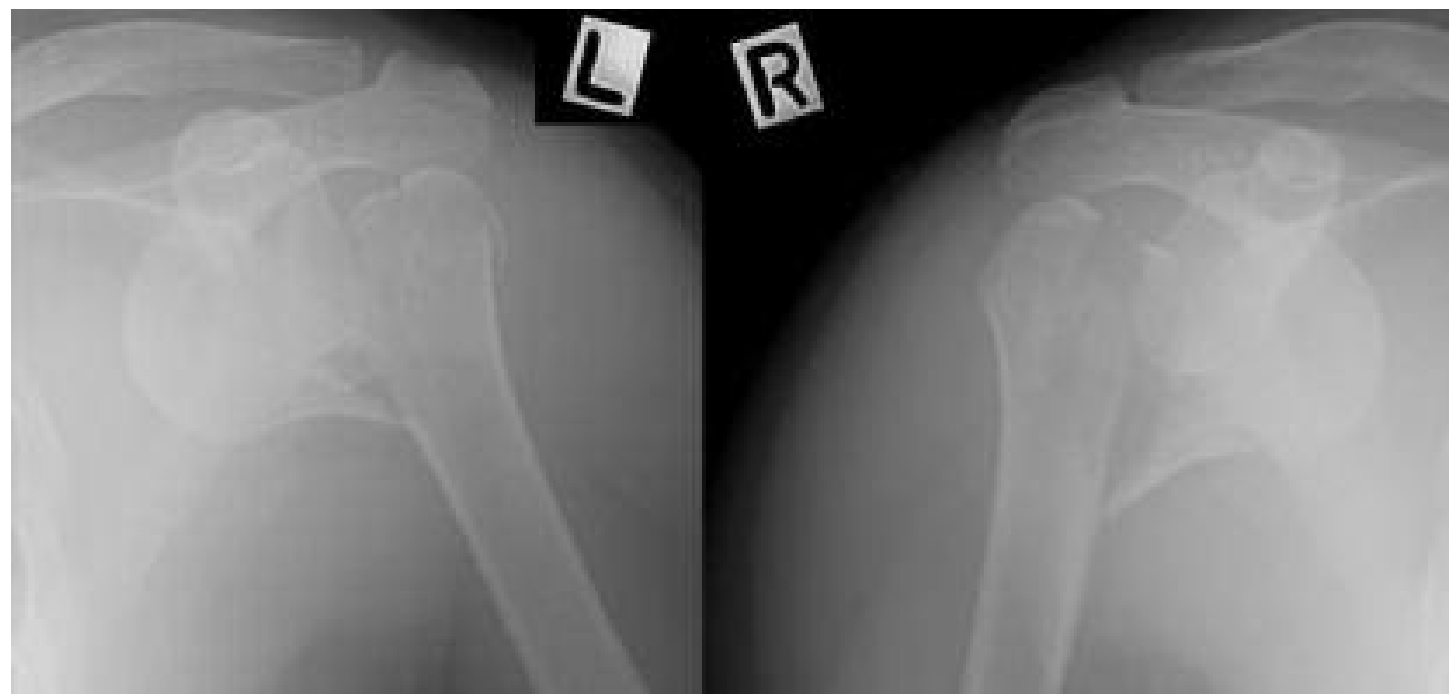

Fig. 1: Radiograph of patient showing bilateral humeral neck fracture dislocation (AP view).

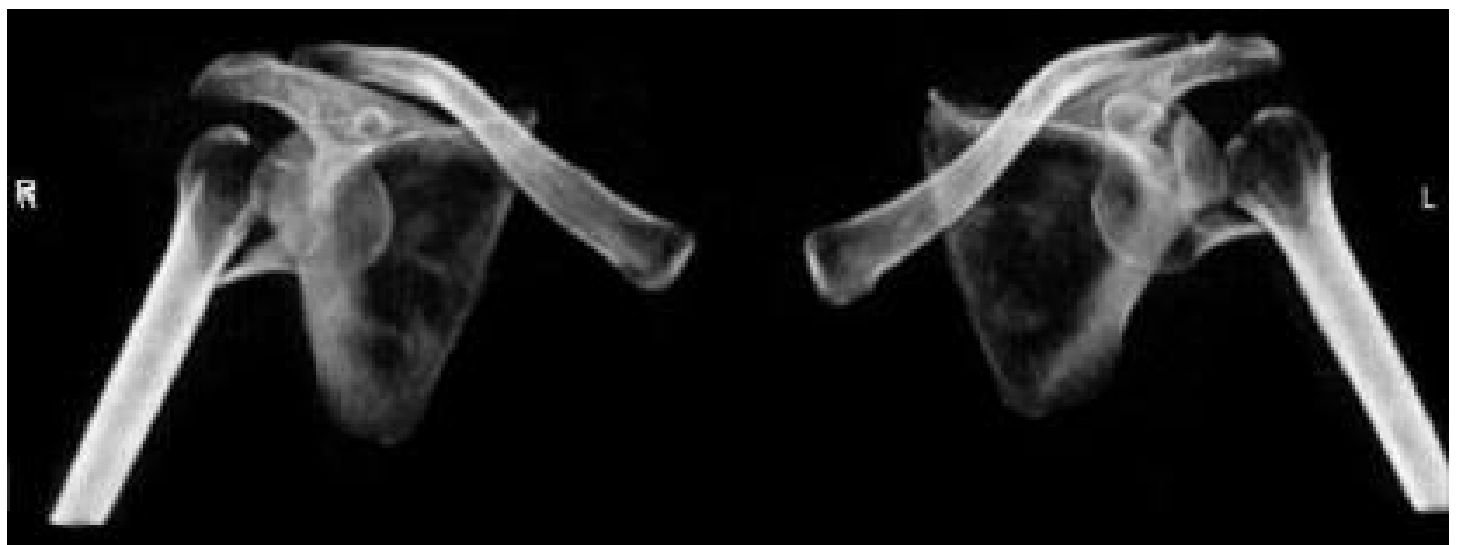

Fig. 2: CT scan image of bilateral humeral neck fracture dislocation (digitally subtracted) 


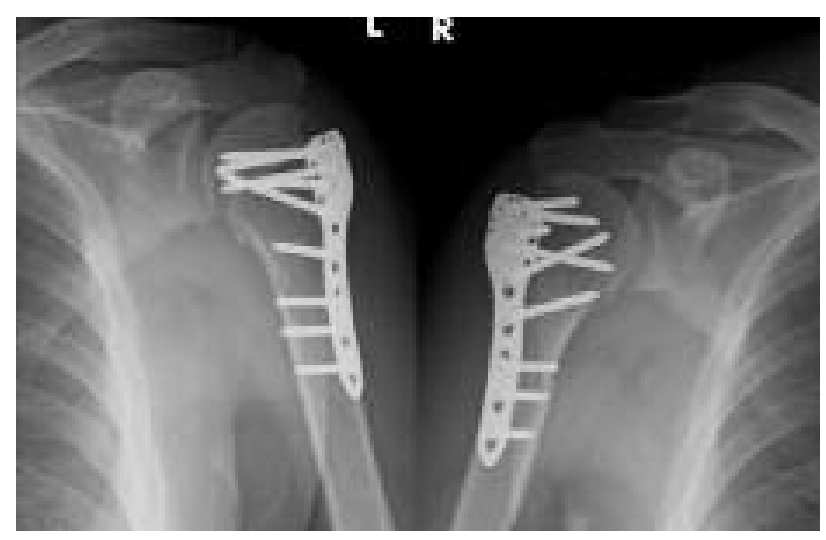

Fig. 3: Radiograph of patient 5 months post operatively (AP view) showing radiological union.

\section{DISCUSSION}

Simultaneous bilateral anterior dislocation of the shoulder associated with a bilateral 3- or 4-part fracture of the proximal humeri is quite rare and only a few cases have been reported in the literature (Table I). In most cases with anterior dislocation of the shoulder, the associated fracture is a 2-part fracture. The present case was unique in that one side was a 3-part anterior fracture-dislocation, and the other was a 4-part anterior fracture-dislocation and the injury was caused by a first seizure episode secondary to subdural gliosis, sequelae from a previous subdural haematoma. To our knowledge, this is the first case report of a patient with $1^{\text {st }}$ occurrence of seizure causing bilateral proximal humeri anterior fracture-dislocations.

Treatment options for proximal humeri fracture dislocations include operative and non-operative methods, but nonoperative treatment of complex (i.e., three part and four-part) fractures is well known to result in malunion and stiffness of the shoulders ${ }^{2}$. Therefore we selected surgical fixation for this patient. There is currently insufficient evidence from published studies to determine the best treatment in active patients with displaced comminuted three or four part fractures of the proximal humerus ${ }^{4}$. There is also no large multi-centre, randomised controlled trial, with long-term follow-up involving treatment of bilateral anterior fracturedislocations of the humeral neck ${ }^{3}$, due to the rarity of this kind of injury (Table I).

We decided to use the PHILOS proximal humerus locking plate for both fractures in this case. Brunner et al ${ }^{5}$ reported good functional outcome in patients who underwent PHILOS proximal humeral locking plate fixation although there were a few complications involving screw penetration into the glenohumeral joint ${ }^{5}$. This patient had a reasonably

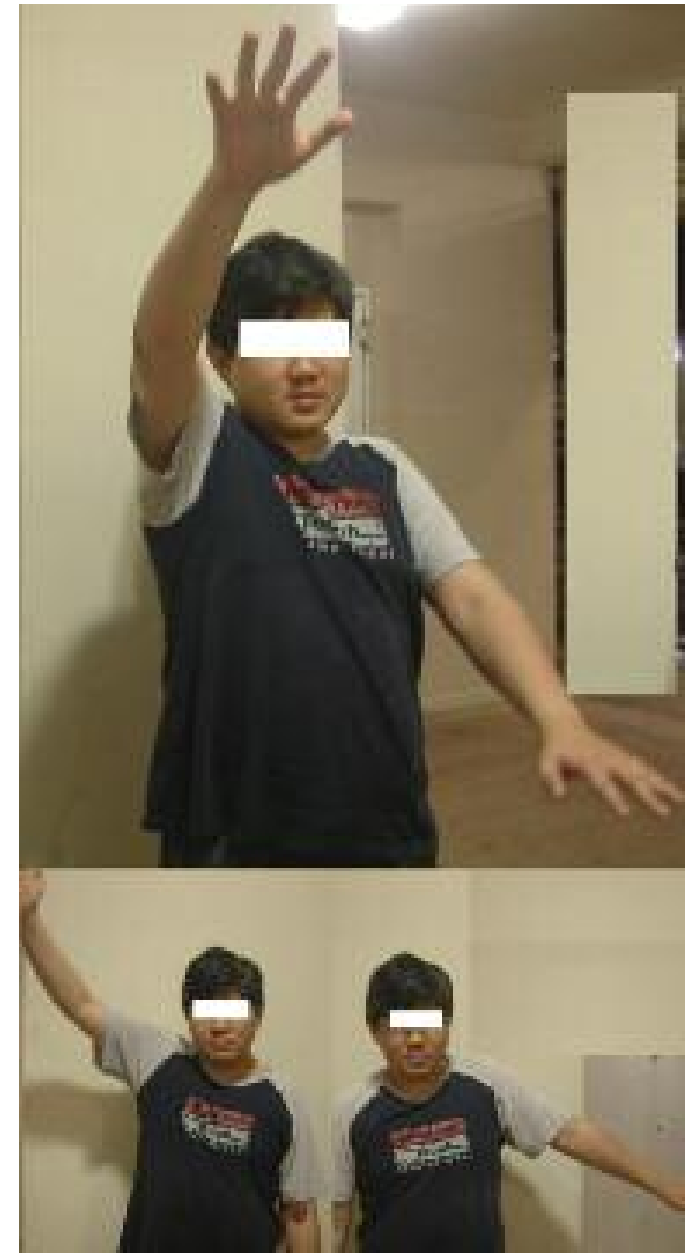

Fig. 4: Pictures of patient showing range of movements for both shoulders.

good functional outcome for his right shoulder (his dominant side) at the 5 month postoperative visit. The poorer functional outcome for his left arm can be attributed to the more severe nature of the fracture. A longer period of follow up is needed to observe for any potential complications.

\section{CONCLUSION}

Bilateral simultaneous anterior dislocation of the shoulder associated with a bilateral 3- or 4-part fracture of the proximal humeri is very rare. Open reduction and internal fixation with PHILOS proximal humeral locking plate is recommended as a suitable option in young active patients with such complex bilateral humeral neck anterior fracture dislocations, however results can be variable. Long term, larger scale studies need to be carried out for further validation of treatment results. 


\section{REFERENCES}

1. Muriel B, Stuart DP, Andrew K. Triple "E" syndrome: Bilateral locked posterior fracture dislocation of the shoulders. Neurology 2001; 56: 1403-4.

2. Neer CS. Displaced proximal humeral fractures: Classification and evaluation. J Bone Joint Surg Am 1970;52(6):1077-89.

3. Robinson CM, LAK Khan, MA Akhtar. Treatment of anterior fracture dislocations of the proximal humerus by open reduction and internal fixation. J Bone Joint Surg Br 2006; 88-B(4): 502-8.

4. Helmy N, Hintermann B. New Trends in the Treatment of Proximal Humerus Fractures. Clin Orthop Relat Res 2006; 442: 100-8.

5. Brunner F, Sommer C, Bahrs C, Heuwinkel R, Hafner C, Rillmann P, et al. Open Reduction and Internal Fixation of Proximal Humerus Fractures Using a Proximal Humeral Locked Plate: A Prospective Multicenter Analysis. J Orthop Trauma 2009; 23(3): $163-72$. 